\title{
A Study on Merits and Demerits of Two Main Gene Silencing Techniques in Mice
}

\author{
Jafar Khezri, Farid Heidari *, Mahdi Shamsara \\ Departnent of Animal Biotechnology National Institue of Genetic Engineering and Biotechnology (NIGEB), Tehran, Iran \\ ${ }^{*}$ Corresponding author: Farid Heidari, Animal Biotechnology National Institute of Genetic Engineering and Biotechnology Shahrak-e Pajoohesh, km 15, \\ Tehran - Karaj Highway,Tehran, Iran. 14965/161, Tehran, Iran. Tel: +98-21-44787314, Fax: +98-21-44787399, E-mail: heidari@nigeb.ac.ir
}

Received: 19 Jun. 2016; Revised: 28 Nov. 2017; Accepted: 10 Jan. 2018; Published online: 11 Aug 2018

\begin{abstract}
Background: Transgenic mice are being considered as invaluable tool in biological sciences towards comprehension of the cause of the genetic diseases. Manipulated embryonic stem (ES) cells are used to produce loss-of-function mutant mice. Microinjection of manipulated ES cells into blastocoel cavity, and morula fusion are the two main techniques in producing transgenic mice. So far, no reports have dealt with the comparison of these two methodologies provide.

Objective: The object of this study was to determine advantages and disadvantages of knockout mouse creation protocols. Materials and Methods: Both blastocyst microinjection and morula aggregation were implemented to produce chimeric mice and the advantages and disadvantages of each technique were evaluated. For this, embryonic stem cells were transfected with a GFP-expression vector. In blastocyst microinjection technique, first transfected ES cell were cultured and appropriate colonies were selected. The cells were microinjected to blastocoel cavity of the expanded blastocyst. In morula aggregation technique, the transfected ES cell colonies were sandwiched between two naked morulas. After $16 \mathrm{~h}$ incubation in a 5\% $\mathrm{CO}_{2}$ at $37^{\circ} \mathrm{C}$ the morulas and infected ES cell were aggregated to produce a new morula. All the injected blastocyst and aggregated morulas were transferred to uterus of foster mice. The new born mice were analyzed for chimera confirmation.

Results: Five chimeric mice (21.75\%) from morula aggregation and eight chimeric mice $(63 \%)$ from blastocyst microinjection were born. The results indicated that both techniques can be used to generate chimeric mouse, however the success rate was higher in blastocyst microinjection.

Conclusion: Morula fusion stands out where the required instrumentations are in place. Furthermore, the quality of ES cells plays a prominent role in the success rate. When the cell quality is low the blastocoel microinjection is recommended. The microinjection technique is more effective than morula aggregation.

Keywords: Blastocoel microinjection, Embryonic stem cell, Loss-of-function mice mutants, Morula fusion
\end{abstract}

\section{Background}

Most of our knowledge about functional analysis of human genes and proteins has obtained via studying the so-called model organisms (1). Animal models have been used to evaluate the role and function of genes, genetic diseases and mechanisms of their progressions, and the efficacy of drugs (2-3). Transgenic animals have been produced in different species including nematodes, flies, birds, frogs and zebra fish (4). Rodents and more specifically mice have received greater attention in modeling human diseases, mainly due to high genetic similarity between the two (5). Additionally, short regeneration time, large numbers of offspring in each generation, ease of manipulation and low maintenance costs of rodents have contributed to the fact that they become models in developmental studies, and functional analysis of genes (6-7). Animal transgenesis and looking for the probable micro-/macro-phenotypes is being considered as a functional analysis tool.

To transfer an exogenous gene into mouse, microinjection of DNA into the pronucleus of male zygotes and use of embryonic stem cells are the methods of

Copyright (C) 2017 The Author(s); Published by National Institute of Genetic Engineering and Biotechnology. This is an open access article, distributed under the terms of the Creative Commons Attribution-NonCommercial 4.0 International License (http://creativecommons.org/licenses/ by-nc/4.0/) which permits others to copy and redistribute material just in noncommercial usages, provided the original work is properly cited. 
choice (8). In the pronuclear microinjection method, the common approach, fine needles are being used for DNA transfection. The DNA will be integrated randomly into the genome and most often multiple copies of the same DNA are followed each other in a tandem fashion (9).

Embryonic stem cells are generally being used to produce loss-of-function mutants (8). Through which and following cell transfection, a recombinant gene construct finds its way into the genome, most likely through homologous recombination. The cells will be developed into blastocyst that can be placed in uterus (oviduct) of the receptive mother, which eventually leads to the birth of a chimeric mouse. Chimeric mice have a combination of cells that are heterozygote for the candidate gene. In following breeding generations, mutants can be obtained that are homozygous for the gene of interest (10). Other less frequently used techniques to generate transgenic mice are; the use of spermatogonia stem cells and nucleus transfer (6).

\section{Objectives}

Animal transgenesis is greatly dependent on lab facilities and technical individuals that are involved. On the other hand, due to being time-consuming and costeffective it would be better to define which technique promises better results. Here, the morula aggregation and blastocyst microinjection have been discussed, addressing their strengths and weaknesses.

\section{Materials and Methods}

Mitomycin C, Genticin, Penicillin, Streptomycine, Neomycin, M16 and M2 media, Plasmid purification kit, Tyrodes acid and leukemia Inhibitory Factor were purchased from Sigma (Germany). PMSG (Folligon) and hCG (Chorulon) were purchased from MSD Animal Health (New Zealand). DMEM, FCS and trypsin was obtained from Gibco BRL (France). RNA and DNA extraction kits were bought from Intron (Korea). Endofree Plasmid Maxi Kit was purchased from Qiagene (USA). High Pure PCR Purification Kit was from Roche (Germany). EW and R1 embryonic stem cells and $p E G F P-C 1$ were kindly donated by Dr. Karim Nayernia at Institute of Molecular Medicine and Cell Therapy, Düsseldorf, Germany and GENEOCELL, Canada.

To generate knockout mouse, ES cells were cultured and electroporated with the gene targeting vector. The genetically-modified cells were selected and transferred into embryos. The modified ES cells along with the cells of embryo were used to produce chimeric mice. Crosses between the chimeras and wild type mice were resulted heterozygous offspring.

\subsection{Embryonic Stem Cell Culture}

EW and R1 cells were defrosted and co-cultured with inactivated MEF cells. Microscopic and expression analyses (cellular markers including Oct4, Nanog and Klf4 via RT-PCR) were revealed that the cells were stem cells.

\subsection{Transfection of Embryonic Stem Cells}

$p E G F P-C 1$ was used to transfect the embryonic stem cells. The plasmid contains GFP, neomycin resistance gene and G418. Endofree Plasmid Maxi Kit was used to purify the plasmids according to the manufacturer's protocol. The plasmid was linearized with ApaII and gel purified with High Pure PCR Purification Kit.

ES cells $\left(10^{7}\right)$ were put in DMEM media for electroporation. Linear construct DNA $(30 \mu \mathrm{g})$ was added to the cells and the mixture was transferred to a $0.4 \mathrm{~mm}$ cuvette for $5 \mathrm{~min}$ at $22{ }^{\circ} \mathrm{C}$ and transfected by electroporation (Bio-Rad, United State). The cells were transfected in the following setting: $250 \mathrm{~V}, 500 \mu \mathrm{F}$ for $7 \mathrm{~ms}$. The cells were added to gelatinized plates after 5 min incubation at $22{ }^{\circ} \mathrm{C}(16)$.

\subsection{Selection of the Appropriate Cells}

Following transfection, the transfected embryonic stem cells were allowed to grow for $48 \mathrm{~h}$. Dead cells were washed off and live cells were selected in a medium containing Neomycin and Genticin $\left(400 \mu \mathrm{g} \cdot \mathrm{mL}^{-1}\right)$. For the first 5 days of culture, subcultures were carried out on a daily basis. In subsequent days, the subcultures were carried out every other day. By day 6 , resistant microscopic colonies were grown. After 10 days, clones become visible. Every clone was transferred to 24-well plates containing nutrient layer of inactive MEF according to (17).

\subsection{Morula and Blastocyst Formation}

At $1 \mathrm{pm}$ at day $1,8 \mathrm{IU}$ PMSG was injected intraperitoneal to four-week old female mice (10-15 NMRI strain). Ovulation of female mice was induced by intraperitoneal injection of 8 IU of hCG after 46$48 \mathrm{~h}$ (three days). The mice (female and fertile male NMRI strain in 1:1 ratio) were allowed to mate. In the following day (day 4), the success of mating was confirmed with the presence of vaginal plug (VP). Finding vaginal plug is a sign of 0.5 day pregnancy. Morula and blastocyst were isolated from 2.5 and 3.5 day old pregnant mice, respectively. Donor mice were euthanized by neck dislocation. The abdomen was opened and following hysterectomy, embryos were collected and washed from uterine horns using M2 media. Embryos were examined microscopically. 
Suitable embryos were transferred to M16 media and kept in an incubator $\left(37^{\circ} \mathrm{C}, 5 \% \mathrm{CO}_{2}\right)(18)$.

\subsection{Blastocysts Microinjection}

Trypsin was used to separate each transfected embryonic stem cell for both EW and R1 cell lines. M2 media (25 $\mu \mathrm{L}$ ) was placed in the center of a microscope dish and covered with mineral oil, 10 blastocysts was added to one side and 1-2 $\mu \mathrm{L}$ of ES cells were added to the other side of the M2. ES cells (8-10) were taken by needle and transferred into the blastocoel cavity via injection. Following injection, blastocysts were transferred to M16 drops and incubated for $1 \mathrm{~h}$ in $\mathrm{CO}_{2}$ incubator at $37{ }^{\circ} \mathrm{C}$. The resulting blastocysts were transferred into the uterus of pseudopregnant 2.5-day old mice by using Sangar methods (19) (Fig. 1).

\subsection{Morula Aggregation}

Sterile needle was used to drill wells at the bottom of a $3-\mathrm{cm}$ cell culture plate. M16 medium was poured down each well. To minimize evaporation, the droplets were covered by mineral oil. The plate was incubated in a $\mathrm{CO}_{2}$ chamber for 1-3 hours before use. Morulas were washed in M2 medium. For morula fusion, removal of zona- pellucida is necessary. For this purpose, isolated morula was placed in droplets of Tyrode's acid solution on a $10 \mathrm{~cm}$ plate and zona was removed. Naked morula was washed with M2 media. The embryos were transferred to the wells mentioned above. Transfected embryonic stem cells of both cell lines EW and R1 were trypsinized and neutralized by ES medium. Cells were separated by a gentle sucking the liquid up and down with a pipette. In each well, initially one morula was placed and ES cells were put next to the first morula and on the other side of the ES cells another morula was placed to form a sandwich Morula-ES-Morula. Plate was transferred to $\mathrm{CO}_{2}$ chamber at $37^{\circ} \mathrm{C}$ and incubated for $24 \mathrm{~h}$ where it remained until Morula-ES-Morula set joined together and converted into blastocysts. The resulting blastocysts were transferred into the uterus of recipient mice.

To evaluate the effect of zona removal, 64 morulas were checked. In each well 2 morulas were placed to fuse together. Blastocysts (30 out of 32) were formed and transferred to the recipient mice similar with chimeric embryos after $24 \mathrm{~h}(20-21)$.

\subsection{Transfer to Recipient Mice}

Chimeric blastocysts (8-10) were transferred to the uterus of pseudo-pregnant NMRI mice. The offspring were analyzed both phenotypically and genotypically (using PCR to detected $e G F P$ ) to determine the success rate. Since each strain have different colors (EW and R1: black and NMRI: white), in the black background patches of white color and vise versa were indicative of chimera production.

\section{Results}

\subsection{Embryonic Stem Cell Culture and Transfection}

Microscopic and expression analysis of cultured cells before and after transfection were pluripotent in both cell lines. Phenotypic changes of transfected embryonic stem cells were evident with a fluorescent microscope after two days. Furthermore, they were able to grow in the presence of Geniticin ( 4 out of 20 clones). No differences were obtained between different cell lines in transfection efficiency and pluripotency (Figs. 1a and b).

\subsection{Morula Fusion and Blastocyst Formation}

Morulas (110 cells) were used in 50 sandwiches with ES cells and produced 48 blastocyts. The blastocysts were monitored under fluorescent microscope and EGFP expression was noted in parts of $\operatorname{ICM}(80 \%)$. The results were indicative of the efficiency of sandwich method (Fig. 1d). Furthermore, blastocyst trophoectoderm cells were rarely showed any sign of GFP expression.

\subsection{Chance of Implantation and Growth of Manipulated Embryos}

Pregnancy data were indicative of lower percentage rate of gestation in female mice receiving the fused morulas. The chance of gestation significantly dropped to $41 \%$.

\subsection{The Results of Fusion Morula}

The sandwich method technique of producing blastocysts from morula was successful. Out of 110 morula + ES

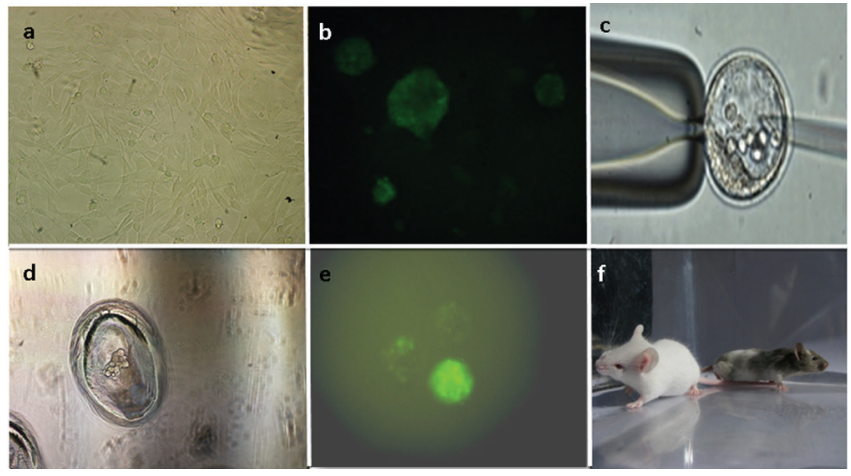

Figure1. a) embryonic stem cell culture next to inactive MEF cells, b) bulk of embryonic stem cells after transfection and expression of GFP, c) microinjection into blactocell cavity, d) morula fusion, e) chimeric blastocysts that express GFP, f) Chimeric mice. 
Khazri J et al.

Table 1. Implantation rate of blastocysts with different modifications.

\begin{tabular}{|c|c|c|c|c|c|c|c|}
\hline $\begin{array}{l}\text { Type blastocyst / } \\
\text { morula }\end{array}$ & $\begin{array}{c}\text { Early } \\
\text { embryo }\end{array}$ & em & $\begin{array}{l}\text { e number of } \\
\text { yos transferred } \\
\text { manipulation }\end{array}$ & $\begin{array}{c}\text { The number } \\
\text { of births } \\
\text { born }\end{array}$ & $\begin{array}{c}\text { The proportion } \\
\text { of births / } \\
\text { transfer }\end{array}$ & $\begin{array}{c}\text { The } \\
\text { chimerism }\end{array}$ & $\begin{array}{c}\text { Gender ratio } \\
\text { of births } \\
\text { (Male:Female) }\end{array}$ \\
\hline Not manipulated & 42 & & 42 & 36 & $85 \%$ & 0 & $50-50$ \\
\hline $\begin{array}{l}\text { Removal of the zona } \\
\text { pellucida }\end{array}$ & 32 & & 30 & 12 & $41 \%$ & 0 & $50-50$ \\
\hline $\begin{array}{l}\text { The melding of } \\
\text { morula }\end{array}$ & 44 & & 19 & 6 & $32 \%$ & 0 & $35-65$ \\
\hline $\begin{array}{l}\text { morula- fusion of } \\
\text { embryonic stem cells }\end{array}$ & 110 & 48 & $\begin{array}{l}23 \text { (EW Strain) } \\
25 \text { (R1 strin) }\end{array}$ & $\begin{array}{l}5 \\
0\end{array}$ & $\begin{array}{c}21.75 \% \\
0\end{array}$ & $\begin{array}{c}0-75 \% \\
0\end{array}$ & $\begin{array}{c}50-50 \\
0\end{array}$ \\
\hline Blastocyst injection & 50 & 36 & $\begin{array}{l}13 \text { (EW strain) } \\
23 \text { (R1 strain) }\end{array}$ & $\begin{array}{l}8 \\
0\end{array}$ & $\begin{array}{c}63 \% \\
0\end{array}$ & $\begin{array}{c}0-75 \% \\
0\end{array}$ & $\begin{array}{c}50-50 \\
0\end{array}$ \\
\hline
\end{tabular}

cells, 48 blastocysts were formed that resulted to the production of 5 chimeric mice (Table 1). None of which were Chimeric R1 and the success rate in EW was $21.75 \%$.

\subsection{Microinjection into Blastocysts}

Blastocysts microinjection and blastocysts formation were suggestive of the success of the procedure. Out of 50 microinjected embryos, 36 blastocysts were formed and resulted in the birth of 8 chimeric mice. No chimeric mouse was born from $\mathrm{R} 1$ cell line and the success rate in EW was $63 \%$. The presence of eGFP was checked via PCR. The chimerism rate was $0-75 \%$. Furthermore, no correlation was noted between the chimerism rate and testing method.

\section{Discussion}

Two main techniques for chimeric mice production are microinjection of modified ES cells in to 3.5 day blastocyst and morula aggregation that leads to the production of new blastocyst with two cell lines. These techniques need trained operators and therefore the success rate is closely dependent to the operator and environmental situation (14)

Successes rate of chimeric production is highly dependent on the cell line and clones that are being used. Some embryonic stem cell lines have low developmental potential towards production of chimeras (22). Optimal conditions should be provided in cultured cells to keep differentiation potential of embryonic stem cell. If culture conditions set to be optimal, chromosomal rearrangements and mutations will be likely to happen (23).

Despite the high production rate of chimeric mice in EW ES cells, similar results were not obtained for
R1 clones. Chimeric embryos produced by R1 lines, found to be dead after transfer.

Out of 13 chimeric mice, 2 of them demonstrated over $50 \%$ chimerism rate, while other 11 had less than $50 \%$. In all these cases, it seemed that the injection of embryonic stem cells was gender-independent and were close to the natural ratio of 1:1.

Because of increased permeability of embryos, removal of embryo zona pellucida made it sensitive to environmental factors (24). Despite the fact that embryos with zona pellucida can be cultured, a reduced survival rate can be seen in embryos without such layer. This lower survival rate might be due to the toxins released from the needles or the wells of culture plate. Additionally, more permeability of naked blastocyst can be considered as the other factor that puts the survival rate under pressure. The success rate of embryo transfer in embryos not covered with zona is being reduced greatly and therefore most of the pregnancies will be failed (3).

Tam and Rossant et al. (2003) reported that blastomeres of 2-8 cell embryos are the best choice for blastomere transfer. The best result that reported was $25 \%$ in morula aggregation and $40 \%$ in blastocyst microinjection (25).

One known feature of female mice, especially in the first pregnancy, would be eating of their own children that are mainly determined by the number of newborns. If the numbers of newborns are low, females tend to kill and remove them to make themselves ready for re-copulation. Therefore instead of introducing 10 embryos obtained from blastocyst microinjection to female mice, here and for the morula aggregation it is being recommended that 20 embryos to be transferred. 
An alternative technique in morula aggregation would be to take advantage of using so called "helper embryos" with manipulated embryos.

\section{Conclusions}

Quality of the cells is the most decisive factor in the success or failure of obtaining chimeric mice from embryonic stem cells. In low quality cells, either the embryos won't survive or the chimerism rate will be low. In cases where the quality of embryonic stem cells are low, blastocoel microinjection would be the method of choice (17).

In summary, monitoring of cells capable of colonizing into chimeric animal can be performed in blastocyst injection as opposed to morula aggregation. This can result in the reduction of chimera quality, particularly for higher-passage. Furthermore, blastocyst microinjection is somewhat more sophisticated than morula aggreagation since it needs both professionals and specialized equipment (26). Thus, blastocyst microinjection is the method of choice, if the required instruments and relevant facilities are provided. Otherwise, morula aggregation can be pursued. Despite the high efficiency of micro-injection, this method requires relatively expensive equipments.

\section{Acknowledgments}

The authors would like to thank stem cell headquarters for providing the required funding (grant No. 1077) and the National Institute for Genetic Engineering and Biotechnology of Iran for allowing us to use Recombinant Mouse Facility under Grant No. 418. The authors would like to thank Dr. Naser Farrokhi at Shahid Beheshti University for rewriting and editing of manuscript.

\section{References}

1. Korzh V, Strähle U. Marshall Barber and the century of microinjection: from cloning of bacteria to cloning of everything. Differentiation. 2002;70(6):221-226. doi:10.1046/ j.1432-436.2002.700601.x

2. Doyle A, McGarry M, Lee N, Lee J. The construction of transgenic and gene knockout/knock in mouse models of human disease. Transgenic Res. 2012;21(2):327-349. doi: 10.1007/ s11248-011-9537-3

3. Wei L. Transgenic animals as new approaches in pharmacological studies. Annu Rev Pharmacol Tox. 1997;37:119-41. doi: 10.1146/annurev.pharmtox.37.1.119

4. Miguel A, Gama Sosa MA, De Gasperi R, Gregory AE. Animal transgenesis an overview. Brain Struct Funct. 2010;214:91-109. doi: 10.1007/s00429-009-0230-8

5. Spencer G. Background on mouse as a model organism. http:// www.genome.gov/10005834.
6. Kumar R, Yadav A, Singh1 V, Vandre R, Singh P, Ramendra Das N, Vineeth M. Transgenic animal technology: Recent advances and applications: A Review. Agri Rev. 2015;36(1):4653. doi:10.5958/0976-0741.2015.00005.7

7. Manis J. Knock out, knock In, knock Down-genetically manipulated mice and the Nobel prize. New Engl J Med. 2007;357:2426-2429. doi:10.1056/NEJMp0707712

8. Gardner RL. Mouse chimeras obtained by the injection of cells into the blastocyst. Nature. 1968;220(5167): 596-597. doi:10.1038/220596a0

9. Hammer RE, Pursel VG, Rexroad CE Jr, Wall RJ, Bolt DJ, Ebert KM, Palmiter RD,. Production of transgenic rabbits, sheep and pigs by microinjection. Nature. 1985;315(6021):680683. doi:10.1038/315680a0

10. Bonin A, Reid SW, Tessarollo L. Isolation, microinjection, and transfer of mouse blastocysts. Methods Mol Biol.2001;158:121134. doi:10.1385/1-59259-220-1:121

11. Rippon HJ and Bishop AE. Embryonic stem cells. Cell prolife. 2004; 37: 23-34. doi:10.1002/pmic.201100107

12. Cibelli JB, Stice SL, Golueke PJ, Kane JJ, Jerry J, Blackwell C, Ponce de León FA, Rob JM. Transgenic bovine chimeric offspring produced from somatic cell-derived stem-like cells. Nature Biotech. 1998;16(7):642-646. doi:10.1038/nbt0798-642

13. Mattos L S, Grant E, Thresher R, and K. Kluckman. Blastocyst microinjection automation. IEEE Trans Inf Techno biomed. 2009;13(5):822-831. doi: 10.1109/TITB.2009.2023664

14. $\mathrm{Hu} \mathrm{M}$, Wei H, Zhang J, Bai Y, Gao F and Li . Efficient production of chimeric mice from embryonic stem cells injected into 4- to 8-cell and blastocyst embryos. J Anim Sci Biotechnol.2013;4(1):4-12. doi: 10.1186/2049-1891-4-12

15. Chimera mouse production by blastocyst injection https://www. eummcr.org/protocols/mouse-production_chimera-mouseproduction-by-blastocyst-injection.pdf. Accessed 26 June 2011.

16. Liou LY, Ko BS, Chang TZ. An efficient transfection method for mouse embryonic stem cells. Methods Mol Bio. 2010;650:145153. DIO: 10.1007/978-1-60761-769-3_12

17. Cartwright EJ. Transgenesis techniques principles and protocols. Third Edition. Human press. Clifton, United states.2009:199-230.

18. Luo C, Zuñiga J, Edison E, Palla S, Dong W, Parker-Thornburg J. Superovulation strategies for 6 commonly used mouse strains. J Am Assoc Lab Anim Sci. 2011:50(4):471-478.

19. Hall B, Limaye A. and Kulkarni A. Overview: generation of gene knockout mice. Curr Protoc Cell Biol 2009;CHAPTER: Unit-19. 1217. doi: 10.1002/0471143030.cb1912s44

20. Plück A, Klasen C. Generation of chimeras by morula aggregation. Methods Mol Biol. 2009;561:219-229. doi: 10.1007/978-1-60327-019-9_14

21. Behringer R, Gertsenstein M, Nagy KV, Nagy A. Manipulating the mouse embryo: A Laboratory Manual. Cold Spring Harbor Laboratory Press. 2014; fourth edition

22. Reid SW, Tessarollo L. Isolation, microinjection and transfer of mouse blastocysts. Methods Mol. Biol. 2009;530:269-285. doi:10.1007/978-1-59745-471-1_14

23. Baharvand, H. and Matthaei, K.I. Culture condition difference for establishment of new embryonic stem cell lines from the 
Khazri J et al.

C57BL/6 and BALB/c mouse strains. In Vitro Cell Dev Biol Anim. 2004;40(3-4):76-81. doi:10.1290/1543-706

24. Sarvari A, Naderi MA, Sadeghi MR, Akhondi MM. A Technique for facile and precise transfer of mouse embryos. Avicenna $J$ Med Biotech. 2013;5(1):62-65.

25. Tam PP and Rossant J. Mouse embryonic chimeras: tools for studying mammalian development. Development. 2003;130(25):6155-6163. doi: 10.1242/dev.00893

26. Eakin GS, Hadjantonakis AK. Production of chimeras by aggregation of embryonic stem cells with diploid or tetraploid mouse embryos. Nat Protoc. 2006;1(3):1145-1153. doi:10.1038/nprot.2006.173 